\title{
The importance of the disciplinary society in leadership skill development and advancement
}

\section{Dr. Tamara Bush, Michigan State University}

Dr. Tamara Reid Bush is an assistant professor in the Department of Mechanical Engineering at Michigan State University. Broadly, Dr. Bush's area of research is whole-body biomechanics. She conducts in vivo experimentation, methods development, and modeling to better understand clinically motivated problems connected with human movement and force generation. The body regions of interest to Dr. Bush are the cervical spine, hands, and skin. Dr. Bush is also a Co-PI for MSU's NSF ADVANCE Institutional Transformation grant. She was selected for the U.S. Bone and Joint Decade Young Investigator Program and is the recipient of the Michigan Campus Compact Award for her work on a rehabilitation tri-cycle for children.

\section{Dr. Laura J Genik, Michigan State University}

Dr. Genik is part of the CoRe teaching faculty at Michigan State University and is widely recognized as a strong educator at the University. She teaches a broad range of courses in Mechanical Engineering and Applied Engineering Sciences at the undergraduate and graduate level as well as the CoRe Experience. 


\section{The importance of the disciplinary society in leadership skill development and advancement}

Several opportunities arise in the disciplinary societies or professional organizations for faculty to begin to develop leadership skills. A disciplinary society or professional organization is considered to be a cohort that includes academics and working professionals focusing on a research or a technical area in a specific field of engineering or science, and has a leadership body, such as an executive committee and other sub-committees. The importance of involvement in the disciplinary society not only pertains to skill development but also promotes research expertise, can establish national recognition, and provides opportunities for collaboration.

The objectives of this work were to gather data, both in qualitative and quantitative forms, regarding the importance of disciplinary society involvement. Because this work was supported by an NSF ADVANCE grant, focus was given to Science, Technology, Engineering and Mathematics (STEM) areas and women in these areas.

Both survey data and focus group data were collected for this research. Survey data were collected from female faculty at a research-based institution (R1) located in the Midwest. Survey questions addressed levels of involvement in societies, pros and cons of involvement, how involvement affected promotion, differences (both positive and negative) between leadership in academia and the professional organization. Additional data were collected through focus groups containing faculty in leadership positions. These participants were either in titled roles such as Dean, Assistant/Associate Dean, Chair or Director or were faculty who held leadership positions in their disciplinary society or professional organization. Also, gender specific questions were asked regarding leadership opportunities, aspirations and mentoring for leadership.

Results of the survey on disciplinary involvement indicated that there was no prescribed method for success and the time-commitment/reward balance should always be evaluated. However, the female faculty indicated multiple benefits including networking with faculty at other institutions, establishing research collaborations, being aware of the latest standards in the field and research topics, and providing the opportunity for leadership positions. It was noted that these opportunities for leadership were available for multiple individuals including graduate students and junior faculty.

Leadership in the professional organization and disciplinary societies was deemed more desirable, particularly by women. The disciplinary society was perceived as an opportunity to try leadership positions. In the society, flexibility was a positive, allowing movement in and out of positions as desired, whereas, the titled roles on campus were not associated with this flexibility.

In the focus groups, the women agreed that having more women in administrative positions might be a positive goal for the institution; everyone agreed that having only male administrators was undesirable. However, performing research (for individuals) and getting grants (for units) 
were seen as more positive and prestigious than doing administrative work. In other words, some participants challenged the assumption on which many of the focus group questions were predicated. Namely, that more women in leadership positions in STEM disciplines is an unqualified good.

Overall, the disciplinary society was viewed to have many positive associations, one being the ability to become involved in leadership positions and develop leadership skills. Disciplinary involvement has the potential to serve many roles throughout academic advancement.

\section{Introduction}

It is a well established fact that women are underrepresented in leadership positions in academia and their number is further diminished in the traditional science, technology, engineering and mathematics fields (STEM). Several researchers have studied aspects of women and leadership. For example, Dworkin ${ }^{1}$, et al. preformed an extensive study with respect to increased mentoring of women for leadership roles emulating foreign programs which are more successful in placing women in leadership positions. Bess and Goldman ${ }^{2}$ investigated the reformulation of leadership paradigms for the broader area of education as a whole drawing the parallels in K-12 and the university. Chesterman ${ }^{3}$, et al., examined the attitudes of senior women in leadership roles (Australian Universities) and what lead to their positions in academia. In the United States, $\mathrm{O}^{\prime} B a_{n n o n}{ }^{4}$, et al., reported on the results of the Leadership Institute, a 4-day program focused on the leadership potential and goals of women faculty. Chesler ${ }^{5}$, et al., brought together tenured and non-tenured faculty in engineering to cultivate a peer mentoring network to further promote women in engineering and leadership roles in academia. However, a paucity of work exists on how involvement in the disciplinary societies is viewed or related to leadership development for women. The main focus of the following work is the fostering of leadership success by first working in such positions in professional and discipline societies as well as understanding the impacts for early career faculty.

Michigan State University was funded through the NSF ADVANCE program for an Institutional Transformation Grant. One of the components of this ADVANCE grant focused on women's leadership. This leadership project had an overarching goal of understanding what factors motivated women faculty to become leaders. Within this overarching goal, the women's leadership team also wanted to better understand the roles their disciplinary/professional societies played in leadership development and advancement.

As a beginning step to meet these goals, the women's leadership team needed to first understand how women participated in their disciplinary societies and professional organizations, and how this involvement was perceived by them, their colleagues and superiors. Here we are considering a disciplinary society or professional organization to be a group that encompasses academics and working professionals emphasizing a research or a technical area in a specific field of engineering or science, and has a leadership body, such as an executive committee and other sub-committees. These societies typically hold conferences in technical areas and oversee the publications of Journals in science and technical areas. Examples of such organizations would be the American Society of Mechanical Engineers, American Society of Civil Engineers, 
American Physical Society, American Sociological Association, and American Society for Engineering Education.

To better understand the involvement of faculty in these organizations survey data and focus group data were collected. Survey questions addressed levels of involvement in societies, pros and cons of involvement, how involvement affected promotion, differences (both positive and negative) between leadership in academia and the professional organization. Additional data were collected through focus groups containing faculty in leadership positions. These participants were either in titled roles such as Dean, Assistant/Associate Dean, Chair or Director or were faculty who held leadership positions in their disciplinary society or professional organization.

\section{Survey Methods/Results}

Survey questionnaire

The leadership team wanted to begin to understand the involvement of women in the disciplinary societies and professional organizations. At the start of the grant, a survey was distributed to tenure stream women faculty in Engineering, Natural Science and Social Science. The purpose of the questionnaire was 1) to collect data on the levels of disciplinary involvement of female faculty who are tenured and compare those to early career faculty, and 2) identify women who are leaders in their disciplinary society (elected, appointed roles). All of the women invited to participate were promised a summary of the findings. Part of the ADVANCE leadership team's goals was to also use the results of the survey as an intervention - specifically for the early career faculty. By distributing the results, and the comments, sharing and learning could occur across women and colleges.

The number of women surveyed was two hundred and forty-seven $(n=247)$. The survey included 27 close-ended questions (yes/no), four short-answer questions (women were asked to provide the specific titles of elected and/or appointed leadership roles held in disciplinary societies), and one open-ended question (women were asked to provide general comments about their disciplinary involvement).

Fifty-nine ( $\mathrm{n}=59$ ) women of 247 surveyed responded to the survey ( $24 \%$ response rate). The response rates were consistent across the three colleges surveyed. These data were analyzed for common themes reported within the open-ended questions. Further, questions with numerical responses were tabulated and reported.

Based on the results of this initial survey of women, focus groups which contained both men and women were then conducted. The addition of the male component to the focus groups introduced a comparison control for the perception of participation in disciplinary societies even though a similar written survey was not conducted with the male tenure stream faculty. Furthermore, the dearth of women in academic leadership roles required the addition of men in these positions. Thus, to obtain a perspective on the discipline society's importance in their ascent in academia men were included in the focus group. 


\section{Survey results}

A summary of the type of involvement for early career faculty (non-tenured) and senior (tenured) faculty is provided in Table 1. Tenured faculty indicated what types of activities they were involved in prior to obtaining tenure, as well as their current activities in their disciplinary societies/professional organizations. Results indicated that the early career faculty were involved in similar levels as their tenured counterparts were pre-tenure for oral/podium presentations (95\% vs 93\%), poster presentations (74\% vs. 65\%), abstract reviewer (42\% vs 50\%), and grant reviewer ( $47 \%$ vs. $55 \%)$. As expected, the tenured women had a higher level of involvement in activities that required a nomination, or large time commitments and might be considered higher visibility positions such as conference chair (5\% vs. $30 \%)$, session organizer ( $26 \%$ vs. 55\%), committee chair (11\% vs. $48 \%)$.

Table 1. Activity involvement with disciplinary societies, reported by percentage within respondent category.

\begin{tabular}{lccc}
\hline $\begin{array}{l}\text { Disciplinary Society } \\
\text { Membership Activity }\end{array}$ & $\begin{array}{l}\text { Percentage of } \\
\text { involvement among } \\
\text { non-tenured } \\
\text { respondents } \\
(n=19)\end{array}$ & $\begin{array}{l}\text { Percentage of } \\
\text { involvement among } \\
\text { tenured respondents- } \\
\text { PRE-TENURE } \\
(n=40)\end{array}$ & $\begin{array}{l}\text { Percentage of } \\
\text { involvement among } \\
\text { tenured respondents }- \\
\text { POST-TENURE } \\
(n=40)\end{array}$ \\
\hline $\begin{array}{l}\text { Oral/Podium } \\
\text { Presentation }\end{array}$ & $95 \%$ & $93 \%$ & $93 \%$ \\
\hline Poster Presentation & $74 \%$ & $65 \%$ & $58 \%$ \\
\hline Invited Paper & $53 \%$ & $63 \%$ & $83 \%$ \\
\hline Panel Member & $32 \%$ & $55 \%$ & $70 \%$ \\
\hline Abstract Reviewer & $42 \%$ & $50 \%$ & $60 \%$ \\
\hline Committee Member & $11 \%$ & $60 \%$ & $75 \%$ \\
\hline Conference Organizer & $16 \%$ & $30 \%$ & $55 \%$ \\
\hline Session Organizer & $26 \%$ & $50 \%$ & $30 \%$ \\
\hline Conference Chair & $5 \%$ & $18 \%$ & $48 \%$ \\
\hline Committee Chair & $11 \%$ & $28 \%$ & $90 \%$ \\
\hline $\begin{array}{l}\text { Manuscript Reviewer for } \\
\text { Journals }\end{array}$ & $100 \%$ & $83 \%$ & $55 \%$ \\
\hline $\begin{array}{l}\text { Editorial Position with a } \\
\text { Journal }\end{array}$ & $5 \%$ & $18 \%$ & $75 \%$ \\
\hline $\begin{array}{l}\text { Grant Reviewer for } \\
\text { funding agency }\end{array}$ & $47 \%$ & $55 \%$ & \\
\hline
\end{tabular}

Participants were also asked to provide general comments with regard to society involvement: was their involvement helpful/ not helpful and how so? If they had any thoughts about how involvement affected their tenure decision, they were asked to include that as well. Overall, participants indicated that their disciplinary involvement provided networking opportunities, increased exposure to other researchers in their field of work, and made them aware of the current level of research expectations. However, participants indicated that there was a balance between time spent and reward, and that needed to be assessed for each individual and in the context of each department. Specific quotes are noted below. 
- "Participating in community leadership (panels, committees, organization) is important in visibility, and in meeting potential collaborators or team members. It is clear that tenure decisions use participation in these activities as evidence for standing in the scientific community."

- "My involvement in reviewing and serving on conference program committees helped me become known to many leaders in my field, which certainly helped for my promotions."

- "It affected my Promotion and Tenure decisions by establishing my reputation for scholarly excellence nationally."

- "There is an optimal level of involvement with regard to time vs. reward. The value of a person's involvement in their disciplinary society will vary by department."

- "All of my involvements were very beneficial to me as far as networking, gaining mentors and lay of the land from senior level faculty around the country."

- "There is no prescribed method for disciplinary involvement and success. However, it is clear that multiple benefits exist from involvement in a disciplinary society. Thus, this topic should be addressed through mentoring, and annual reviews with early career faculty."

Women were also asked to indicate their preference on workshops. Ten topics for workshops were suggested in the questionnaire and the top three preferred workshops included with percentage of respondents and tenure status indicated:

How to assume a leadership role How to self promote

How to say no and still succeed
$42 \%$ early career faculty $/ 25 \%$ tenured faculty $47 \%$ early career faculty $/ 35 \%$ tenured faculty $42 \%$ early career faculty $/ 38 \%$ tenured faculty

\section{Focus Groups Methods/Results}

Focus group methods

A total of 54 individuals were involved in eight focus groups (24 women participated in the female focus groups and 30 in the male focus groups). Four groups were composed of women and four composed of men. Each focus group consisted of one category either: Chairs/Directors, Assistant/Associate Deans, Deans or disciplinary society leaders.

Five main questions were asked in each focus group. The questions were:

1. What were the factors that led to your decision to take on your current leadership position?

2. Did you have a mentor during your leadership role?

3. What are the challenges of being in a leadership role? 
4. a. Why don't more women seek administrative positions? (Female group)

b. In your experience, if you have offered a leadership position to a woman, what were the reasons she shared about why she did or didn't take it? (Male group)

5. What are the advantages of being in a leadership role?

\section{Focus group results}

Through the inclusion of the Chairs/Directors, Assistant/Associate Deans, and Deans, in focus groups, some general information about titled leadership roles and differences between male and female leaders was obtained. Then, through the focus groups containing leaders in their disciplinary societies, more specific information about the value of involvement in such organizations was gathered. The following summarizes these data:

\section{What were the factors that led to your decision to take on your current leadership position? What are the advantages of being in a leadership role?}

Most of what were identified as reasons for taking a leadership position, were also identified as advantages of being in a leadership role. Thus, the results from both questions are presented together.

The men and women agreed on the reasons for taking on a leadership position with many talking about making a difference in faculty or student lives, seeing some change in the organization and thinking their leadership would help with the change, or they were asked to be in the role and thought they could do it well. Several concurred with the statement that it was an opportunity for creativity and problem-solving and an intellectual challenge of a different kind (compared to research). The most common statement made by women in these groups was "I felt I could make a difference". All three titled groups of leaders agreed that being a leader gave them a greater understanding of the University, helped them learn things they would not have otherwise known, and introduced them to other leaders.

\section{Did you have a mentor during your leadership role?}

Focus group results indicated that women in leadership positions had mentors, while men did not use the term "mentor". The men did say that they would seek advice from colleagues who had been in that role or a similar role and referred to these contacts as "networking".

\section{What are the challenges of being in a leadership role?}

Men noted that budget cuts and doing more with less was one of the common challenges. Also, managing people was seen as a challenge; with some saying that usually it was only one or two difficult people that caused issues. 
While it was generally acknowledged that family issues are primarily women's issues, there was also consensus that men generally had a built-in support system and women just had two jobs. For the women leaders, the style of leadership was also considered a challenge; other people expected typical sympathetic female behavior. Therefore, women administrators were asked to make accommodations that men would not be asked to make. Furthermore, in departments with multi-cultural staff, men from some cultures have difficulty taking direction from women administrators.

\section{Why don't more women seek administrative positions? (Female group)}

In one group, women said they had women in their college who were in charge of large multimillion dollar research grants and they would not think of asking them to give these up for an administrative position. It was noted that administrative positions are not glamorous. Participants indicated that individuals who assume them have to like paperwork and managing details. Also, there was some debate with regard to the role family obligations played for women. Some women said straight out, "I couldn't do this if I still had kids at home and was married." Another said she thought having a family was the best preparation for her job (just like being an air traffic controller) and said she looked forward to coming home and having some "comic relief" after her day at the office. Many said this was of concern to young women and new faculty.

\section{In your experience, if you have offered a leadership position to a woman, what were the reasons she shared about why she did or didn't take it? (Male group)}

One male leader said he never had a woman turn down a position he offered; in the Chairs group one said he offered an administrative position to a woman and she took it because it was a clear interest of hers. Men noted the following examples or statements women used to decline a leadership role:

- Was a "star in her field" or had a 9-month endowed chair and didn't want to exchange that status for a 12-month administrative position.

- Had young children.

- Had a woman who did not go through the five year chair review because the position was not what she wanted to do with her life.

- One of the Associate/Assistant Deans said there were so few women in his (science) field and administration was seen as less desirable than research and teaching.

\section{Specifically with regard to the focus groups that contained leaders in the disciplinary societies, the following points were noted.}

The male focus groups, which were generally senior individuals as they held leadership positions in their societies, suggested that although involvement is important, they felt that the University needed to reconsider what role professional or disciplinary society leadership plays in the life of faculty. If this voluntary service is viewed as extraneous by titled administrators (such as in 
annual reviews and promotion evaluation) and its value not conveyed, fewer faculty will participate. The male focus groups did indicate that involvement in the disciplinary societies provided opportunities to connect with other researchers, who could then be named when going through the promotion process.

The majority of the women commented that involvement in the disciplinary society provided personal and organizational benefits with some noting involvement was critical, "this is a criterion I'm judged on for promotion and tenure". Also, women viewed University administration as entirely different than leadership in a professional society. For example, university administrative positions are generally longer term and leadership in a professional society shorter term. The risks associated with titled university roles have more to do with having to eventually return to the group (e.g. having to make unfavorable decisions while in administration) while the rewards for leadership in professional societies had to do with collegiality. Women did consistently indicate that they thought men were more willing to put themselves forward for a leadership position in the society than women.

\section{Conclusions and Implications}

Involvement in the disciplinary society/professional organization is perceived by women to have many advantages. These included networking, establishing themselves as a leader in their field, and making connections with potential reviewers of proposals and publications. Additionally, when involved in a leadership position in the society, skill development occurred. Also, women liked the idea of leadership in a disciplinary society over a titled role.

The society offers opportunities that may not be available in a title role on campus, particularly in fields with small numbers of women. The appealing aspects of leadership in a society include flexibility in the sense that individuals are not committed to a 3 or 5 year appointment, also, societies usually have a higher percentage of females and a sense of belonging may exist because of the higher number of women, and a different climate. Finally, leadership in a society might be considered easier to "try out" as they can participate in a position, and move to another role if the original position is not meeting their needs.

In some positions, specifically the executive and the conference chair positions, several organizational and political skill development opportunities can arise. These skills include the management of activities, management of people and development of budgets which provide the necessary preparation for individuals to serve in titled roles later in their careers.

Thus, involvement in the disciplinary organization can have several advantages, however, as noted by the faculty, the involvement level and the reward as viewed by superiors must be considered, particularly for early career faculty so that an optimal balance is achieved. 


\section{References}

1. Terry Morehead Dworkin, Virginia Maurer, Cindy A. Schipani, Career mentoring for women: New horizons/Expanded methods, Business Horizons, Volume 55, Issue 4, July-August 2012, Pages 363-372, ISSN 0007-6813, 10.1016/j.bushor.2012.03.001.

2. James L Bess, Paul Goldman, Leadership ambiguity in universities and $K-12$ schools and the limits of contemporary leadership theory, The Leadership Quarterly, Volume 12, Issue 4, Winter 2001, Pages 419-450, ISSN 1048-9843, 10.1016/S1048-9843(01)00090-X.

3. Colleen Chesterman, Anne Ross-Smith, Margaret Peters, “Not doable jobs!” Exploring senior women's attitudes to academic leadership roles, Women's Studies International Forum, Volume 28, Issues 2-3, May-June 2005, Pages 163-180, ISSN 0277-5395, 10.1016/j.wsif.2005.04.005.

4. O’Bannon, D., Garavalia, L., Renz, D., and McCarther, S. (2010). Successful Leadership Development for Women STEM Faculty, Leadership Manage. Eng. 10, SPECIAL ISSUE: Women in Civil Engineering, 167-173.doi: 10.1061/(ASCE)LM.1943-5630.0000080

5. Naomi Chesler, Peg Single, Borjana Mikic, On Belay: Peer-Mentoring and Adventure Education for Women Faculty in Engineering. Journal of Engineering Education, July 2003, pp. 257-262 